\title{
Immediate and Late Outcome of Excimer Laser and Balloon Coronary Angioplasty: A Quantitative Angiographic Comparison Based on Matched Lesions
}

\author{
SIPKE STRIKWERDA, MD, PHD, ELINE MONTAUBAN VAN SWIJNDREGT, \\ DAVID P. FOLEY, MD, ERIC BOERSMA, MSc, VICTOR A. UMANS, MD, PhD, \\ REIN MELKERT, MD, PATRICK W. SERRUYS, MD, PHD, FACC
}

Rotterdam, The Netherlands

Objectives. This study sought to compare acute lumen changes and late lumen narrowing during and after excimer laser-assisted balloon angioplasty, measured by quantitative coronary angiography, with the immediate and long-term outcome of balloon angioplasty alone.

Background. Although excimer laser coronary angioplasty is used as an adjunct or alternative to balloon angioplasty, limited comparative data exist regarding the immediate and long-term efficacy of excimer laser-assisted balloon angioplasty versus balloon angioplasty alone.

Methods. A series of 53 lesions in 47 consecutive patients successfully treated with excimer laser-assisted balloon angioplasty were individually matched after completion of 6-month follow-up angiography with $\mathbf{5 3}$ successfully treated balloon angioplasty lesions according to vessel location, preprocedural minimal lumen diameter and reference diameter. Immediate and longterm angiographic results were assessed by an automated lumen contour detection algorithm.

Results. Before intervention in the laser and balloon angio-

Currently, transluminal balloon angioplasty (1) remains the most common applied technique for the percutaneous treatment of patients with coronary artery disease. In an attempt to improve primary success and to reduce acute complication and long-term restenosis rates associated with balloon coronary angioplasty, a variety of novel techniques and devices have been introduced over the past 10 years $(2,3)$. Excimer laser coronary angioplasty removes atherosclerotic plaque by laser ablation, that is, vaporization of plaque tissue by short pulses of excimer laser radiation delivered through a fiberoptic cath-

From the Cardiac Catheterization Laboratory, Thoraxcenter, University Hospital Dijkzigt, Erasmus University, Rotterdam, The Netherlands. Dr. Foley is a Fellow of the Irish Heart Foundation, Dublin, Ireland. This study was presented in part at the 66th Scientific Sessions of the American Heart Association, Atlanta, Georgia, November 1993.

Manuscript received October 7, 1994; revised manuscript received April 14 1995, accepted May 24, 1995.

Address for correspondence: Dr. Patrick W. Serruys, Catheterization Laboratory, Thoraxcenter, Bd 416, University Hospital Dijkzigt, Erasmus University Rotterdam, P.O. Box 1738, 3000 DR Rotterdam. The Netherlands. plasty groups, respectively, minimal lumen diameter (mean \pm SD) was $0.73 \pm 0.47$ and $0.74 \pm 0.46 \mathrm{~mm}$, and reference diameter was $2.71 \pm 0.42$ and $2.72 \pm 0.41 \mathrm{~mm}$. Laser angioplasty was followed by adjunctive balloon dilation in 50 lesions. Mean balloon diameter at maximal inflation was similar in both treatment groups $(2.61 \pm 0.32$ and $2.65 \pm 0.38 \mathrm{~mm}$, respectively), resulting in similar minimal lumen diameters after intervention of $1.77 \pm 0.41$ and $1.78 \pm 0.34 \mathrm{~mm}$, respectively. At follow-up angiography, minimal lumen diameter after excimer laserassisted balloon angioplasty was $1.17 \pm 0.63 \mathrm{~mm}$, and that after balloon angioplasty alone was $1.46 \pm 0.67 \mathrm{~mm}(p=0.02)$. The angiographic restenosis rates at follow-up using the $50 \%$ diameter stenosis cutof criterion were $57 \%$ and $34 \%$, respectively $(p=0.02)$.

Conclusions. Quantitative angiographic analysis of a matched group of 106 successfully treated coronary lesions showed a similar immediate outcome but reduced long-term efficacy of excimer laser-assisted balloon angioplasty compared with that after balloon angioplasty alone.

(J Am Coll Cardiol 1995;26:939-46)

eter $(4,5)$. Since the first patient with coronary artery disease was treated with a xenon chloride excimer laser in August 1988 (6), excimer laser angioplasty has been increasingly used as an adjunct or alternative to balloon angioplasty (7-11). Although laser angioplasty is followed by balloon dilation in more than $90 \%$ of cases ("to debulk and dilate"), it is hypothesized that reduction of atherosclerotic tissue mass by laser ablation with or without adjunctive balloon dilation may be more effective in enlarging the vessel lumen than balloon angioplasty alone. Data on thousands of patients undergoing excimer laser coronary angioplasty have now been accumulated in prospective, observational registries $(10,11)$. The reported primary success and complication rates of excimer laser angioplasty with or without adjunctive balloon dilation compared favorably with those of balloon angioplasty alone, specifically in complex coronary artery lesions (8-14). However, comparative data on the immediate and long-term efficacy of excimer laser versus balloon coronary angioplasty are limited $(8,10)$, and a reliable assessment of long-term results of excimer laser angioplasty is 
hampered by low angiographic follow-up rates in most published reports.

The aim of the present study was to compare the immediate and long-term efficacy of excimer laser versus balloon coronary angioplasty in matched patient groups with similar baseline stenosis characteristics and anginal patterns and complete late angiographic follow-up. In the past, this comparative approach of lesion matching has been satisfactorily applied by our group to compare the short- and long-term outcomes of directional atherectomy and balloon angioplasty (15) as well as stent implantation and balloon angioplasty as a surrogate for randomized trials (16). Indeed, these matching studies have accurately predicted the angiographic outcomes of recently completed randomized investigations (17-20) comparing these new interventional techniques with conventional balloon coronary angioplasty.

\section{Methods}

Patients. For the purpose of the present study, a consecutive series of patients with native coronary artery lesions successfully treated by excimer laser-assisted balloon angioplasty was prospectively included. All patients had symptomatic coronary artery disease or objective evidence of myocardial ischemia, or both. A successful treatment was defined as procedural success $(<50 \%$ residual diameter stenosis at the end of the intervention) without death, nonfatal myocardial infarction, bypass graft surgery or repeat angioplasty during the hospital period. Within the time frame of this study, 50 patients completed a 6-month follow-up period after a successful procedure for 56 coronary artery lesions. This patient cohort represents almost a fourth of the population treated with the excimer laser at our institution until now and reflects our experience with the device after completion of a learning curve. All patients except one ( $98 \%$ of eligible patients) underwent actual follow-up angiography an average $( \pm \mathrm{SD})$ of $5.7( \pm 1.5)$ months after intervention. Two patients successfully treated with excimer laser angioplasty for a chronic total coronary occlusion could not be satisfactorily matched with patients treated by balloon angioplasty according to the angiographic criteria described later. The study group, therefore, included 47 patients with 53 coronary artery lesions successfully treated by excimer laser-assisted balloon angioplasty who were individually matched with patients who had undergone successful conventional balloon coronary angioplasty. The clinical and angiographic details of the two treatment groups are described in Table 1.

Laser procedure. The laser system consisted of a xenon chloride excimer laser (Advanced Interventional Systems, Inc.) emitting light pulses at a wavelength of $308 \mathrm{~nm}$ with a pulse duration of $-200 \mathrm{~ns}$ and a repetition rate of 20 to $30 \mathrm{~Hz}$. Over the wire laser catheters of 1.3-, 1.6-, and 2.0-mm diameter with a concentric multifiber arrangement around a central guide wire lumen were used. Laser fluence at the catheter tip was set at levels ranging from 45 to $65 \mathrm{~mJ} / \mathrm{mm}^{2}$. For anticoagulation, aspirin and heparin were given intravenously with additional
Table 1. Baseline Characteristics of Matched Patients and Lesions Before Excimer Laser Coronary Angioplasty and Balloon Coronary Angioplasty

\begin{tabular}{lcc}
\hline & $\begin{array}{c}\text { ELCA } \\
(\mathrm{n}=47)\end{array}$ & $\begin{array}{c}\text { PTCA } \\
(\mathrm{n}=53)\end{array}$ \\
\hline Age (yr) & $55.8 \pm 9.2$ & $57.4 \pm 8.6$ \\
Male gender $(\%)$ & 77 & 79 \\
Angina class (CCS) (\%) & 2 & \\
I & 26 & 32 \\
II & 57 & 53 \\
III & 15 & 13 \\
IV & 53 & 53 \\
Lesions (no.) & & \\
Location (no.) & 27 & 27 \\
LAD & 17 & 17 \\
RCA & 9 & 9 \\
LCx & 12 & 12 \\
Total occlusions (no.) & $0.73 \pm 0.47$ & $0.74 \pm 0.46$ \\
Minimal lumen diameter (mm) & $2.71 \pm 0.42$ & $2.72 \pm 0.41$ \\
Reference diameter (mm) & $73 \pm 17$ & $73 \pm 17$ \\
Diameter stenosis (\%) & $0.59 \pm 0.50$ & $0.60 \pm 0.49$ \\
Minimal lumen cross-sectional area $\left(\mathrm{mm}^{2}\right)$ & $5.92 \pm 1.83$ & $5.95 \pm 1.83$ \\
Reference area (mm $\left.{ }^{2}\right)$ & $90 \pm 9$ & $90 \pm 9$ \\
Area stenosis (\%) & $8.1 \pm 3.6$ & $6.6 \pm 3.1$ \\
Lesion length (mm) & & \\
Plaque area (mm ${ }^{*}$ & $10.1 \pm 4.9$ & $8.0 \pm 6.0$ \\
\hline
\end{tabular}

${ }^{*}$ For nontotal obstructions only ( $n=41$ in both groups). $p=$ NS for all variables. Data presented are mean value $\pm \mathrm{SD}$ or number or percent of patients or lesions. CCS = Canadian Cardiovascular Society; ELCA = excimer laser coronary angioplasty; $\mathrm{LAD}=$ left anterior descending coronary artery; $\mathrm{LCx}=$ left circumflex coronary artery; PTCA = balloon coronary angioplasty; RCA = right coronary artery.

doses of heparin as required to keep the activated clotting time $>400 \mathrm{~s}$ for the duration of the procedure. The laser angioplasty procedure as performed in our institution has been described in detail previously (21). If, after one pass with the laser catheter, the residual diameter stenosis was $>50 \%$, the lesion was passed with a larger diameter laser catheter, or adjunctive balloon dilation was performed. In three patients with three lesions, stand-alone laser angioplasty resulted in a satisfactory angiographic result. Before and after the laser procedure (and adjunctive balloon dilation), angiography was performed in multiple projections after intracoronary administration of nitroglycerin to control vasomotor tone. After intervention, the patients were monitored for $24 \mathrm{~h}$, and 12-lead electrocardiograms were recorded and cardiac enzyme levels were measured twice a day. Six hours after the procedure, the sheaths were removed. After recanalization of a total or subtotal occlusion, a heparin infusion was maintained until the next morning; then, heparin was discontinued, and the sheaths removed. The only specific postprocedural drug regimen consisted of aspirin for 6 months. The patients were evaluated at the outpatient clinic at 1 and 6 months after the procedure or earlier if dictated by recurrence of symptoms. Late follow-up angiography was performed after intracoronary administration of nitroglycerin, replicating exactly the projections and settings used during the intervention. 
Quantitative coronary angiography. For each treated segment, the minimal lumen and reference diameters before and after the procedure and at follow-up angiography were derived from multiple matched projections. All cineangiograms were analyzed using the computer-based Cardiovascular Angiography Analysis System (CAAS), which has been described and validated previously (22-25). This system permits an objective and reproducible quantification of the minimal lumen diameter of a coronary segment in absolute millimeters. A computerderived estimation of the original arterial dimension at the site of obstruction (assuming there is no disease present) is used to define the interpolated reference diameter. The percent diameter and area stenosis as well as the cross-sectional area (in $\mathrm{mm}^{2}$ ), are then calculated. The length of the lesion (in $\mathrm{mm}$ ) is determined from the diameter function on the basis of a curvature analysis. The area between the actual and reconstructed contours at the obstruction site is a measure of the amount of atherosclerotic plaque and is expressed in $\mathrm{mm}^{2}$. Because the algorithm cannot measure total occlusions, a value of $0 \mathrm{~mm}$ was imputed for the minimal lumen diameter and a value of $100 \%$ for percent diameter stenosis. In these cases, the reference diameter after intervention was substituted for the reference diameter before intervention or at follow-up, respectively. To obtain the mean balloon diameter, the largest balloon at maximal inflation was measured in a nonforeshortened projection.

Matching process. To compare coronary lumen changes occurring during and after excimer laser-assisted balloon angioplasty with the short- and long-term changes during and after balloon angioplasty alone, a consecutive series of 53 lesions successfully treated by excimer laser ( \pm balloon) angioplasty were matched with 53 successfully treated balloon angioplasty lesions. The coronary artery tree was subdivided into 15 segments according to the American Heart Association guidelines, and the lesions were individually matched according to preprocedural minimal lumen diameter, reference diameter and vessel location. The principles of matching by quantitative angiography are as follows $(15,16,26)$ : 1) The angiographic dimensions of matched lesions are assumed to be identical; and 2) the observed difference in minimal lumen and reference diameters between the two identical lesions must be within the range of reproducibility of the quantitative analysis system for lesion measurement $(1 \mathrm{SD}=0.10 \mathrm{~mm})(22-25)$. Thus, lesion pairs were selected in which the difference between these angiographic variables did not exceed $0.2 \mathrm{~mm}$ (twice the variability, 95\% confidence limits). After completion of matching for these three angiographic variables, the patients' anginal status was introduced as an additional, clinical characteristic to enhance and refine the matching process. The data base from which the balloon angioplasty lesions were selected contains quantitative angiographic data on 3,736 coronary lesions treated by balloon angioplasty, enabling satisfactory matching of lesions and patients undergoing different interventions. Matching was performed by an independent unbiased physician (R.M.) without knowledge of procedural or clinical outcomes according to the aforementioned criteria.
Assessment of restenosis. The following criteria were used to asses the long-term efficacy of excimer laser and balloon coronary angioplasty: 1) The primary angiographic variable of interest in this study representing the final angiographic outcome of either intervention was the minimal lumen diameter at follow-up. 2) The second criterion for restenosis chosen was $\geq 50 \%$ diameter stenosis at follow-up, derived from the minimal lumen diameter and reference diameter of the vessel. This restenosis rate according to the categoric (dichotomous) approach was used because in clinical practice decision making is still based on this cutoff criterion, and it is the conventionally recognized angiographic definition of restenosis. 3) The third variable uses the gain in minimal lumen diameter achieved during an intervention and the subsequent lumen loss during follow-up related to the vessel size (reference diameter), enabling a comparison among vessels of different caliber (26). The relative gain is calculated as (Postintervention minimal lumen diameter - Preintervention minimal lumen diameter)/ Reference diameter, and relative loss as (Postintervention minimal lumen diameter - Follow-up minimal lumen diameter)/Reference diameter. The relation between relative gain and relative loss was studied by means of regression analysis because there is experimental and clinical evidence of a proportional relation between the extent of vessel wall injury inflicted by an intervention (reflected angiographically as lumen gain) and the subsequent reparative response, that is, intimal hyperplasia (reflected angiographically as lumen loss) $(15,16,26-32)$. 4) The net gain in lumen improvement at follow-up normalized for vessel size is described by the net gain index: (Follow-up minimal lumen diameter - Preintervention minimal lumen diameter)/Reference diameter. 5) The loss index, as proposed by Kuntz et al. (33) and defined as late loss divided by acute gain, was calculated as (Postintervention minimal lumen diameter - Follow-up minimal lumen diameter)/ (Postintervention minimal lumen diameter - Preintervention minimal lumen diameter).

Statistical analysis. All values obtained from quantitative angiographic analysis and derived variables are expressed as mean value $\pm S D$. Differences between the two groups and within each group were assessed by two-factor repeatedmeasures analysis of variance. The Bonferroni correction was applied for multiple comparisons. Simple regression analysis was used to evaluate the relative gain/relative loss relation in each group. To compare the linear regressions for the two treatment groups, multiple regression analysis was performed introducing the type of intervention as a dummy variable. A p value $<0.05$ was considered to indicate a significant difference.

\section{Results}

Matching. Baseline clinical and quantitative angiographic characteristics of the two matched patient groups are presented in Table 1. No significant differences in gender, age or anginal status were observed. Matching for angiographic variables was satisfactory with identical distribution of stenosis location and similar minimal lumen diameter and reference 

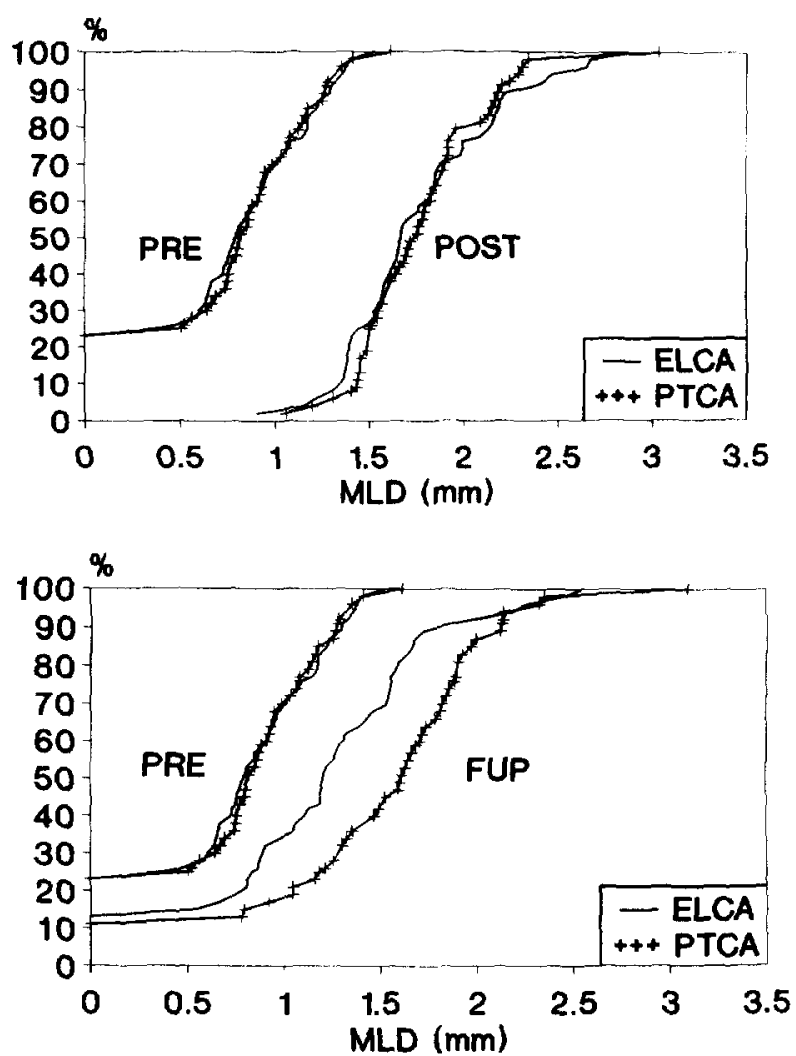

Figure 1. Cumulative frequency curves to illustrate the immediate (top) and long-term (bottom) changes in minimal lumen diameter (MLD) induced by excimer laser-assisted balloon angioplasty (ELCA) and balloon angioplasty alone (PTCA) as assessed by quantitative coronary angiography. FUP $=$ at follow-up; PRE (POST) $=$ before (after) intervention.

diameter measurements in both groups: $0.73 \pm 0.47$ and $2.71 \pm$ $0.42 \mathrm{~mm}$ for the laser angioplasty group and $0.74 \pm 0.46$ and $2.72 \pm 0.41 \mathrm{~mm}$ for the balloon angioplasty group, respectively. The cumulative distribution curves for the minimal lumen diameter before either intervention (Fig. 1) can be seen to overlap suitably. Other lesion variables (diameter stenosis, minimal lumen cross-sectional area, reference area, area stenosis, lesion length and plaque area) also did not differ significantly between groups. Qualitative descriptors of lesion morphology derived from visual analysis of coronary angiograms included the presence of a branch point in the stenotic segment ( $47 \%$ in the laser group vs. $49 \%$ in the balloon group), lesion calcification ( $23 \%$ vs. $13 \%$, respectively) and relation of the lesion to a coronary bend ( $11 \%$ vs. $8 \%$, respectively), which were not significantly different between groups. In both groups, 12 total occlusions were present before intervention ( $23 \%$ of total group). Thus, this matching technique resulted in the selection of two patient groups with similar clinical and preprocedural stenosis variables.

Immediate results. The immediate outcome after excimer laser-assisted balloon angioplasty and balloon angioplasty alone as assessed by quantitative coronary angiography is shown in Figure 1 (top) and Tables 2 and 3. The reference
Table 2. Comparative Quantitative Angiographic Analysis of Immediate and Follow-Up Results of Excimer Laser ( \pm Balloon) Angioplasty and Balloon Angioplasty Alone in 53 Coronary Lesions

\begin{tabular}{lcc}
\hline & $\begin{array}{c}\text { ELCA } \\
\text { (mean } \pm \text { SD) }\end{array}$ & $\begin{array}{c}\text { PTCA } \\
\text { (mean } \pm \text { SD) }\end{array}$ \\
\hline Minimal lumen diameter $(\mathrm{mm})$ & & \\
Pre & $0.73 \pm 0.47$ & $0.74 \pm 0.46$ \\
Post & $1.77 \pm 0.41$ & $1.78 \pm 0.34^{*}$ \\
F-up & $1.17 \pm 0.63$ & $1.46 \pm 0.67 \dagger$ \\
Reference diameter (mm) & & \\
Pre & $2.71 \pm 0.42$ & $2.72 \pm 0.41$ \\
Post & $2.84 \pm 0.49$ & $2.69 \pm 0.44$ \\
F-up & $2.75 \pm 0.57$ & $2.78 \pm 0.56$ \\
Diameter stenosis (\%) & & \\
Pre & $73 \pm 17$ & $73 \pm 17$ \\
Post & $37 \pm 11$ & $34 \pm 10^{*}$ \\
F-up & $57 \pm 21$ & $47 \pm 24 \dagger$ \\
Minimal lumen cross- & & \\
$\quad$ sectional area $\left(\mathrm{mm}^{2}\right)$ & & \\
Pre & $0.59 \pm 0.50$ & $0.60 \pm 0.49$ \\
Post & $2.60 \pm 1.26$ & $2.57 \pm 1.05^{*}$ \\
F-up & $1.37 \pm 1.15$ & $2.02 \pm 1.36 \dagger$ \\
Reference area $\left(\mathrm{mm}^{2}\right)$ & & \\
Pre & $5.92 \pm 1.83$ & $5.95 \pm 1.83$ \\
Post & $6.49 \pm 2.32$ & $5.84 \pm 1.99$ \\
F-up & $6.17 \pm 2.70$ & $6.29 \pm 2.68$ \\
Area stenosis $(\%)$ & & $90 \pm 9$ \\
Pre & $60 \pm 13$ & $55 \pm 13^{*}$ \\
Post & $77 \pm 15$ & $66 \pm 20 \dagger$ \\
F-up & & \\
\hline
\end{tabular}

${ }^{*} p<0.01$ within groups. $; p<0.05$ interaction. F-up $=$ at follow-up; Post $=$ after intervention; Pre = before intervention; other abbreviations as in Table 1.

diameter did not change significantly after either intervention (from $2.71 \pm 0.42$ to $2.84 \pm 0.49 \mathrm{~mm}$ in the laser angioplasty group vs. $2.72 \pm 0.41$ to $2.69 \pm 0.44 \mathrm{~mm}$ in the balloon angioplasty group). Both procedures resulted in a significant improvement in minimal lumen diameter; postprocedural minimal lumen diameter was $1.77 \pm 0.41 \mathrm{~mm}$ in the laser group and $1.78 \pm 0.34 \mathrm{~mm}$ in the balloon-only group. Percent diameter stenosis after intervention was not different between groups ( $37 \pm 11 \%$ vs. $34 \pm 10 \%$, respectively). Excimer laser angioplasty alone resulted in significant lesion debulking (minimal lumen diameter from $0.73 \pm 0.47$ to $1.30 \pm 0.29 \mathrm{~mm} \mathrm{[p}<$ $0.001]$; $55 \%$ of acute gain in minimal lumen diameter in

Table 3. Procedural Variables Derived From Quantitative Coronary Angiography

\begin{tabular}{lccc}
\hline & $\begin{array}{c}\text { ELCA } \\
(\text { mean } \pm \text { SD) }\end{array}$ & $\begin{array}{c}\text { PTCA } \\
(\text { mean } \pm \text { SD) }\end{array}$ & $\begin{array}{c}\mathrm{p} \\
\text { Value }\end{array}$ \\
\hline MLD after ELCA alone $(\mathrm{mm})$ & $1.30 \pm 0.29$ & - & - \\
Balloon size $(\mathrm{mm})$ & $2.61 \pm 0.32$ & $2.65 \pm 0.38$ & 0.34 \\
& $(\mathrm{n}=50)$ & $(\mathrm{n}=53)$ & \\
MLD after intervention $(\mathrm{mm})$ & $1.77 \pm 0.41$ & $1.78 \pm 0.34$ & 0.97 \\
Absolute gain (mm) & $1.04 \pm 0.54$ & $1.03 \pm 0.57$ & 0.96 \\
Relative gain & $0.39 \pm 0.21$ & $0.38 \pm 0.21$ & 0.88 \\
\hline
\end{tabular}

MLD = minimal lumen diameter; other abbreviations as in Table 1. 
Table 4. Follow-Up Variables Derived From Quantitative Coronary Angiography

\begin{tabular}{lccc}
\hline & $\begin{array}{c}\text { ELCA } \\
\text { (mean } \pm \text { SD) }\end{array}$ & $\begin{array}{c}\text { PTCA } \\
(\text { mean } \pm \text { SD) }\end{array}$ & $\begin{array}{c}\text { P } \\
\text { Value }\end{array}$ \\
\hline MLD at follow-up (mm) & $1.17 \pm 0.63$ & $1.46 \pm 0.67$ & 0.02 \\
DS $\geq 50 \%$ at follow-up $(\%)$ & 57 & 34 & 0.02 \\
Absolute loss (mm) & $0.60 \pm 0.63$ & $0.31 \pm 0.64$ & 0.02 \\
Relative loss & $0.23 \pm 0.25$ & $0.12 \pm 0.24$ & 0.01 \\
Net gain index & $0.16 \pm 0.21$ & $0.27 \pm 0.27$ & 0.02 \\
Loss index & $0.63 \pm 0.77$ & $0.35 \pm 1.01$ & 0.10 \\
\hline
\end{tabular}

DS = diameter stenosis; other abbreviations as in Tables 1 and 3.

the laser group). However, after adjunctive balloon dilation in $50(94 \%)$ of 53 lesions, total acute gain in minimal lumen diameter after laser-assisted balloon angioplasty was similar to that after balloon angioplasty alone $(1.04 \pm 0.54$ vs. $1.03 \pm$ $0.57 \mathrm{~mm}$, respectively). Balloon diameter at maximal inflation was similar in both groups $(2.61 \pm 0.32$ and $2.65 \pm 0.38 \mathrm{~mm}$, respectively). Because of this nearly identical immediate outcome, any differences in late outcome may be attributable to the type of treatment received (laser angioplasty or balloon dilation).

Figure 2. Scattergram of values obtained for relative gain in the group undergoing coronary excimer laser-assisted balloon angioplasty (ELCA) (top) or balloon angioplasty alone (PTCA) (bottom) and relative loss during the follow-up period. A linear relation emerges for both techniques; however, a steeper slope of the regression line is found in the excimer laser-assisted balloon angioplasty group $(0.71 \mathrm{vs}$. $0.30, \mathrm{p}=0.05$ ).
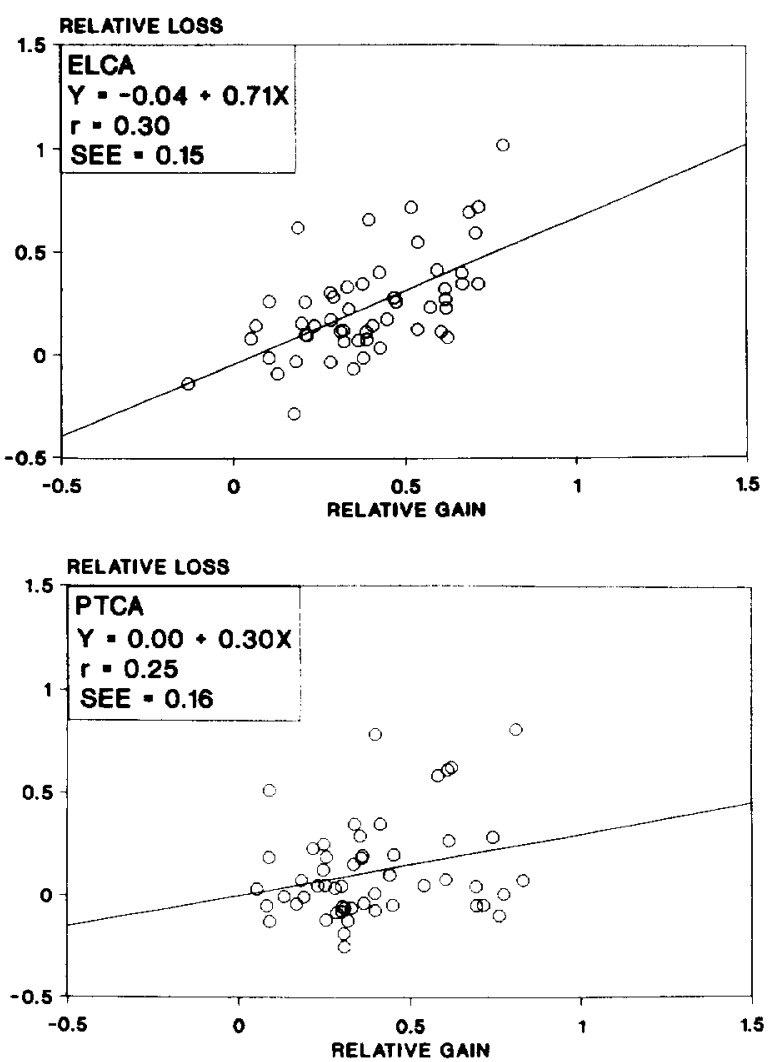

Long-term results. Quantitative angiographic results at follow-up are summarized in Figure 1 (bottom) and Tables 2 and 4. The minimal lumen diameter at follow-up was significantly smaller after excimer laser-assisted balloon angioplasty than after balloon angioplasty alone $(1.17 \pm 0.63$ vs. $1.46 \pm$ $0.67 \mathrm{~mm}$, respectively, $\mathrm{p}=0.02$ ), with consequently higher percent diameter stenosis $(57 \pm 21 \%$ vs. $47 \pm 24 \%$, respectively, $\mathrm{p}=0.02)$ and lower net gain index $(0.16 \pm 0.21$ vs. $0.27 \pm 0.27$, respectively, $p=0.02$ ). Although relative lumen gain was equal in both treatment groups, relative lumen loss in the laser angioplasty group was almost twice as much as in the balloon angioplasty group $(0.23 \pm 0.25$ vs. $0.12 \pm 0.24$, respectively, $\mathrm{p}=0.01$ ). Simple regression analysis demonstrated a linear relation between relative gain and relative loss for each treatment group (Fig. 2), although the coefficient of correlation was comparatively low in both groups. The slope of the regression line was steeper in the excimer laser group (0.71) than in the balloon angioplasty group $(0.30)$; this difference was of borderline statistical significance $(p=0.05)$. Loss index was greater in the laser angioplasty group than in the balloon angioplasty group $(0.63 \pm 0.77$ vs. $0.35 \pm 1.01$, respectively), although this difference did not reach statistical significance $(p=0.10)$. According to the categoric approach, using the conventional $50 \%$ diameter stenosis cutoff criterion, the angiographic restenosis rate at follow-up was $57 \%$ after excimer laser-assisted balloon angioplasty and $34 \%$ after balloon angioplasty alone $(p=0.02)$.

\section{Discussion}

Matching studies. With the introduction of excimer laser angioplasty for the treatment of coronary artery disease (411), it was hoped that, besides improvement of acute success and complication rates (8-14), the incidence of restenosis with this new intervention would be reduced in comparison with conventional balloon angioplasty. So far, direct comparisons of excimer laser versus balloon coronary angioplasty in the treatment of lesions with similar angiographic morphology are few (34). Before the results of prospective, randomized trials became available, the comparative evaluation of matched coronary lesions undergoing different interventions was recognized as a valid method of comparing the short- and long-term efficacy of a new technique relative to conventional balloon angioplasty $(15,16,26,35)$. In fact, the comparative quantitative angiographic analysis of matched lesions undergoing different interventions has accurately predicted the angiographic outcomes of subsequent randomized investigations of directional atherectomy $(15,17,18)$ and coronary stenting $(16,19,20)$ versus balloon angioplasty. Applying the same methodology of lesion matching presented an excellent opportunity to investigate the immediate and long-term results of excimer laser angioplasty compared with conventional balloon coronary angioplasty.

Immediate results. The immediate angiographic outcome of excimer laser-assisted balloon angioplasty was similar to that of conventional balloon angioplasty despite significant lesion debulking by excimer laser ablation, which accounted for $55 \%$ 
of the total gain in minimal lumen diameter in the laser-treated group. We recently demonstrated (21) that elastic recoil of the vessel wall after excimer laser-assisted balloon angioplasty is similar to that after balloon angioplasty alone using balloon catheters of equal size. The present findings may point toward, at least in part, a dilatory ("Dotter") effect of excimer laser angioplasty rather than effective debulking of plaque tissue as in directional atherectomy $(15,21,26,36)$. Coaxial delivery of excimer laser pulses in arteries is accompanied by the generation of shock waves (37) and the repetitive formation and collapse of vapor bubbles causing explosive dilation and invagination of the adjacent arterial segment $(38,39)$. Examination by intravascular angioscopy of the morphologic changes induced by pulsed excimer laser angioplasty in peripheral and coronary arteries (40) has revealed dissection flaps, fractures of plaques and abundant tissue remnants that corresponded to angiographic findings of haziness and dissections. Channels recanalized by multifiber laser catheters that emitted fluences of 40 to $60 \mathrm{~mJ} / \mathrm{mm}^{2}$ were small and irregular, indicating insufficient tissue removal. In a recent quantitative angiographic study (41), it was found that this may be largely a result of laser catheter undersizing rather than inefficient tissue removal by laser ablation. However, we complied with the general methodology not to use laser catheters with a diameter larger than two-thirds of the reference diameter of the vessel to reduce the risk of perforation, thereby limiting lumen gain by laser ablation. The procedural outcome of excimer laserassisted balloon angioplasty may, hence, largely be determined by the therapeutic effect of the "adjunctive" balloon dilation. The relative contribution of true debulking, that is, tissue removal by laser vaporization, and mere dilatory effects by excimer laser angioplasty in the recanalization of arterial obstructions remains to be determined.

Restenosis. Although acute lumen gain was similar in both treatment groups, the laser-treated group exhibited significantly greater lumen loss during follow-up, resulting in a significantly smaller minimal lumen diameter at follow-up. Why is there more restenosis after excimer laser angioplasty $(7,9,10,32)$ ? Two possible explanations may exist for this different behavior of the treated artery during follow-up:

1. In the achievement of a similar degree of acute lumen gain, excimer laser-assisted balloon angioplasty may inflict more damage to the vessel wall than balloon dilation alone. The intraluminal delivery of excimer laser pulses has been shown $(38,39)$ to induce extensive damage to the adjacent arterial wall, including medial necrosis, dissection planes filled with red blood cells and internal elastic lamina abrasion. Schwartz et al. $(27,28)$ have shown a strong relation between the extent of vessel wall injury during intervention and the degree of subsequent neointimal thickening in a swine model. Greater damage (injury) to the treated vessel segment would provoke a proportionally greater proliferative response (repair). Excimer laser angioplasty may give rise to a strong reparative, inflammatory reaction that would possibly not occur to that extent after the comparatively lesser trauma of balloon dilation. The more aggressive neointimal response may be appreciated angiographically as greater lumen loss at follow-up. A quantitative angiographic analysis of excimer laser-assisted angioplasty of saphenous vein graft lesions suggested (42) that aggressive laser tissue debulking may adversely affect restenosis.

2. Excimer laser irradiation itself may inherently provoke a unique response of the vessel wall that precipitates more extensive neointimal hyperplasia. At the cellular level, the ultraviolet radiation from an excimer laser may be mutagenic (43), promoting the proliferation and growth of smooth muscle cells and production of extracellular matrix.

Linear regression analysis has shown a correlation between relative gain at intervention (as an index of vessel wall injury) and relative loss during follow-up (as an index for neointimal hyperplasia) after balloon angioplasty $(26,44)$, Wiktor stent implantation (30), directional atherectomy $(15,31)$ and excimer laser-facilitated coronary angioplasty (32). In our patients, a statistically significant, though somewhat weak, correlation was found between relative gain and relative loss in both treatment groups. More important, however, is the observation that the regression line is much steeper in the laser-treated group (slope 0.71 vs. $0.30 ; p=0.05$ ). Also, the loss index (late loss divided by acute gain) was greater in the laser-treated group than in the balloon angioplasty group ( 0.63 vs. $0.35, p=0.10$ ). These findings imply a greater reactive response of the vessel wall after excimer laser-assisted balloon angioplasty than after conventional balloon angioplasty for any given level of lumen gain. These observations are in disagreement with the model for restenosis as proposed by Kuntz et al. (33), which describes a uniform behavior of the vessel wall during follow-up, independent of the device used for intervention. Loss index in that model was consistently observed at 0.47 for balloon angioplasty, stenting or atherectomy. More recently, Bittl et al. (32) reported a loss index after excimer laser-facilitated coronary angioplasty of 0.58 . Although of borderline statistical significance, the differential findings in the present study with respect to lumen renarrowing after intervention suggest that there may in fact be a device-specific influence on the neointimal response independent of lumen increase. Comparisons of late angiographic outcome in patients treated by coronary balloon angioplasty, stent implantation and directional atherectomy by our group have previously suggested the possibility of such a device-specific effect (45-47).

Study limitations. The present study has several limitations:

1. It is an observational study in relatively small patient groups using a new interventional technique under continuous development. Future modifications in catheter design and treatment protocols may improve immediate and late results.

2. Because only successful procedures are compared, the present study does not give insight into the primary success rates of the two techniques. In observational registries, excimer laser angioplasty with or without adjunctive balloon dilation has been found to be associated with a higher primary success rate than balloon angioplasty alone, particularly in lesions with complex morphology (8-14). Consequently, selection bias 
cannot be totally excluded. Although not statistically significant, there was a tendency toward treatment of somewhat longer lesions with the excimer laser than with balloon angioplasty. Longer lesions have been found to be independently associated with greater lumen loss during follow-up after coronary balloon angioplasty (29) but not after excimer laserfacilitated angioplasty (32).

3 . Although the two groups are well matched for several angiographic variables and some patient characteristics (age, gender and angina class), procedure-related and other patient variables, such as diabetes or previous treatment at the lesion site, are not included in the analysis. However, in a previous matching study (15) it was shown that inclusion of additional clinical variables reduces the number of lesions that can be successfully matched without changing the nature of the angiographic findings. A prospective, randomized investigation is currently being completed in The Netherlands to assess the immediate and long-term efficacy of excimer laser and balloon angioplasty in the treatment of long $(>10 \mathrm{~mm})$ coronary lesions (AMRO trial) $(48,49)$. In view of the reasonably accurate prediction of the angiographic outcomes of recent major multicenter randomized trials of two new devices with conventional balloon angioplasty $(17-20)$ by previous matching studies such as the present one $(15,16)$, the final outcome of randomized comparisons of excimer laser and balloon coronary angioplasty $(34,49)$ may well have been predicted in the present observational study.

Conclusions. In this study of matched coronary lesions, excimer laser angioplasty (with adjunctive balloon dilation in 94\% of cases) achieved a similar immediate angiographic result as conventional balloon angioplasty but, as a result of more pronounced lumen renarrowing, was associated with a significantly less favorable long-term angiographic outcome.

We acknowledge Jaap Pameyer and the angiographic core laboratory Cardialysis for the quantitative angiographic analyses.

\section{References}

1. Gruentzig AR, Senning A, Siegenthaler WE. Nonoperative dilatation of coronary artery stenosis: percutaneous transluminal coronary angioplasty N Engl J Med 1979;301:61-8.

2. Waller BF, "Crackers, breakers, stretchers, drillers, scrapers, shavers, burners, welders and melters": the future treatment of atherosclerotic coronary artery disease? A clinical-morphologic assessment. J Am Coll Cardiol 1989:13:969-87.

3. King SB III. Role of new technology in balloon angioplasty. Circulation 1991:84:2574-9.

4. Isner JM. Donaldson RF, Deckelbaum LI, et al. The excimer laser: gross, light microscopic and ultrastructural analysis of potential advantages for use in laser therapy of cardiovascular disease. J Am Coll Cardiol 1985;6:1102-9.

5. Singleton DL, Paraskevopoulos G, Taylor RS, Higginson LAJ. Excimer laser angioplasty: tissue ablation, arterial response, and fiber optic delivery. IEEE J Quantum Elect 1987;OE-23:1772-82.

6. Litvack F, Grundfest W, Eigler N, et al. Percutaneous excimer laser coronary angioplasty. Lancet 1989:2:102-3.

7. Karsch KR, Haase KK, Voelker W, Baumbach A, Mauser M, Seipel L. Percutaneous coronary excimer laser angioplasty in patients with stable and unstable angina pectoris: acute results and incidence of restenosis during 6-month follow-up. Circulation 1990;81:1849-59.
8. Cook SL, Eigler NL, Shefer A, Goldenberg T, Forrester JS, Litvack F. Percutaneous excimer laser coronary angioplasty of lesions not ideal for balloon angioplasty. Circulation 1991;84:632-43.

9. Bittl JA, Sanborn TA. Excimer laser-facilitated coronary angioplasty: relative risk analysis of acute and follow-up results in 200 patients. Circulation 1992:86:71-80

10. Bittl JA, Sanborn TA, Tcheng JE, Siegel RM, Ellis SG, for the Percutaneous Excimer Laser Coronary Angioplasty Registry. Clinical success, complications and restenosis rates with excimer laser coronary angioplasty. Am J Cardiol 1992;70:1533-9.

11. Litvack F, Eigler N, Margolis $\mathbf{J}$, et al, for the ELCA investigators. Percutaneous excimer laser coronary angioplasty: results in the first consecutive 3.000 patients. J Am Coll Cardiol 1994:23:323-9.

12. Werner GS, Buchwald A, Unterberg C, Voth E, Kreuzer H, Wiegand V. Recanalization of chronic total coronary arterial occlusions by percutaneous excimer-laser and laser-assisted angioplasty. Am J Cardiol 1990;66:1445-50.

13. Israel DH, Marmur JD, Sanborn TA. Excimer laser-facilitated balloon angioplasty of a nondilatable lesion. J Am Coll Cardiol 1991;18:1118-9.

14. Eigler NL, Weinstock B. Douglas JS, et al., for the ELCA investigators. Excimer laser coronary angioplasty of aorto-ostial stenoses: Results of the excimer laser coronary angioplasty (ELCA) registry in the first 200 patients. Circulation 1993;88(Pt 1):2049-57.

15. Umans VA, Hermans W, Foley DP, et al. Restenosis after directional coronary atherectomy and balloon angioplasty: comparative analysis based on matched lesions. J Am Coll Cardiol 1993;21:1382-90.

16. de Jaegere PP, Hermans WR, Rensing BJ, Strauss BH, de Feyter PJ, Serruys PW. Matching based on quantitative coronary angiography as a surrogate for randomized studies: comparison between stent implantation and balloon angioplasty of native coronary artery lesions. Am Heart J 1993;125:310-9.

17. Topol EJ, Leya F, Pinkerton CA, et al, for the CAVEAT Study group. A comparison of directional atherectomy with coronary angioplasty in patients with coronary artery disease. N Engl J Med 1993;329:221-7.

18. Adelman AG, Cohen EA, Kimball BP, et al. A comparison of directional atherectomy with balloon angioplasty for lesions of the left anterior descending coronary artery. N Engl J Med 1993;329:228-33.

19. Serruys PW, de Jaegere P, Kiemeneij F, et al. A comparison of balloonexpandable-stent implantation with balloon angioplasty in patients with coronary artery disease. N Engl J Med 1994;331:489-95.

20. Fischman DL, Leon MB, Baim DS, et al. A randomized comparison of coronary-stent placement and balloon angioplasty in the treatment of coronary artery disease. N Engl J Med 1994;331:496-501.

21. Strikwerda S, Montauban van Swijndregt E, Melkert R, Serruys PW. Quantitative angiographic comparison of elastic recoil after coronary excimer laser-assisted balloon angioplasty and balloon angioplasty alone. J Am Coll Cardiol 1995;25:378-86.

22. Reiber JHC, Serruys PW, Kooijman CJ. et al. Assessment of short-, medium-, and long-term variations in arterial dimensions from computerassisted quantitation of coronary cineangiograms. Circulation 1985;71: $280-8$.

23. Reiber JHC, Serruys PW. Quantitative coronary angiography. In: Marcus ML, Schelbert HR, Skorton DJ, Wolf GL, editors. Cardiac Imaging. A Companion to Braunwald's Heart Disease. Philadelphia: Saunders, 1991: $21,3-80$.

24. Serruys PW, Foley DP, de Feyter PJ, editors. Quantitative Coronary Angiography in Clinical Practice, Part One. Dordrecht: Kluwer Academic Publishers, 1994:1-87.

25. Haase J, Di Mario C, Slager CJ, et al. In-vivo validation of on-line and off-line geometric coronary measurements using insertion of stenosis phantoms in porcine coronary arteries. Cathet Cardiovasc Diagn 1992;27:16-27.

26. Serruys PW, Foley DP, de Feyter PJ. Restenosis after coronary angioplasty: a proposal of new comparative approaches based on quantitative angiography. Br Heart J 1992;68:417-24.

27. Schwartz RS, Murphy JG, Edwards WD, Camrud AR, Vlietstra RE, Holmes DR. Restenosis after balloon angioplasty: a practical proliferative model in porcine coronary arteries. Circulation 1990;82:2190-200.

28. Schwartz RS, Huber KC, Murphy JG, et al. Restenosis and the proportional neointimal response to coronary artery injury. J Am Coll Cardiol 1992;19: $267-75$.

29. Rensing BJ, Hermans WRM, Vos J, et al, on behalf of the CARPORT Study Group. Angiographic risk factors of luminal narrowing after coronary balloon angioplasty using balloon measurements to reflect stretch and elastic recoil at the dilatation site. Am J Cardiol 1992:69:584-91. 
30. de Jaegere P, Serruys PW, Bertrand M, et al. Angiographic predictors of recurrence of restenosis after Wiktor stent implantation in native coronary arteries. Am J Cardiol 1993;72:165-70.

31. Umans VAWM, Robert A, Foley D, et al. Clinical, histologic and quantitative angiographic predictors of restenosis after directional coronary atherectomy: a multivariate analysis of the renarrowing process and late outcome. J Am Coll Cardiol 1994;23:49-58.

32. Bittl JA, Kuntz RE, Estella P, Sanborn TA. Baim DS. Analysis of late lumen narrowing after excimer laser-facilitated coronary angioplasty. J Am Coll Cardiol 1994;23:1314-20.

33. Kuntz RE, Gibson CM, Nobuyoshi M, Baim DS. Generalized model of restenosis after conventional balloon angioplasty, stenting and directional atherectomy. J Am Coll Cardiol 1993;21:15-25.

34. Vandormael M, Reifart N, Preuster W, et al. Comparison of excimer laser angioplasty and rotational atherectomy with balloon angioplasty for complex lesions: ERBAC Study final results [abstract]. J Am Coll Cardiol 1994;23: $57 \mathrm{~A}$.

35. Glantz SA. It is all in the numbers. J Am Coll Cardiol 1993;21:835-7.

36. Kimball BP, Bui S, Cohen EA, Carere RG, Adelman AG. Comparison of acute elastic recoil after directional coronary atherectomy versus standard balloon angioplasty. Am Heart J 1992;124:1459-66.

37. Tomaru T, Geschwind HJ, Boussignac G, Lange F, Tahk SJ. Characteristics of shock waves induced by pulsed lasers and their effects on arterial tissue: comparison of excimer, pulse dye, and holmium YAG lasers. Am Heart J 1992;123:896-904.

38. van Leeuwen TG, van Erven L, Meertens JH, Motamedi M, Post MJ, Borst C. Origin of arterial wall dissections induced by pulsed excimer and mid-infrased laser ablation in the pig. J Am Coll Cardiol 1992;19:1610-8.

39. van Leeuwen TG, Meertens JH, Velema E. Post MJ, Borst C. Intraluminal vapor bubble induced by excimer laser pulse causes microsecond arterial dilation and invagination leading to extensive wall damage in the rabbit. Circulation 1993;87:1258-63.
40. Nakamura F, Kvasnicka J, Uchida Y, Geschwind HJ. Percutaneous angioscopic evaluation of luminal changes induced by excimer laser angioplasty. Am Heart J 1992;124:1467-72.

41. Safian RD, Freed M, Lichtenberg A, et al. Are residual stenoses after excimer laser angioplasty and coronary atherectomy due to inefficient or small devices? Comparison with balloon angioplasty. J Am Coll Cardiol 1993;22:1628-34

42. Strauss BH, Natarajan MK, Batchelor WB, et al. Quantitative angiographic analysis of vein graft lesions treated with excimer laser angioplasty: immediate and follow-up results [abstract]. J Am Coll Cardiol 1994;23:449A.

43. Feld MS, Kramer JR. Mutagenicity and the XeCl excimer laser: a relationship of consequence? Am Heart J 1991;122:1803-5.

44. Foley DP, Melkert R, Serruys PW. Influence of coronary vessel size on renarrowing process and late angiographic outcome after successful balloon angioplasty. Circulation 1994;90:1239-51.

45. Serruys PW, Foley DP, Kirkeeide RL, King SB III. Restenosis revisited: insights provided by quantitative coronary angiography. Am Heart J 1993; 126:1243-67.

46. Foley DP, Serruys PW. Restenosis after percutaneous interventions: the evolving angiographic perspective. Cor Artery Dis 1993;4:1129-36.

47. Umans VAWM, Keane D, Foley D, Boersma E, Melkert R, Serruys PW. Optimal use of directional coronary atherectomy is required to ensure long-term angiographic benefit: a study with matched procedural outcome after atherectomy and angioplasty. J Am Coll Cardiol 1994;24:1652-9.

48. Strikwerda S, Koolen JJ, de Feyter PJ, Sprangers RLH, Tijssen JGP, Serruys PW. Excimer laser coronary angioplasty in The Netherlands: preamble for a randomized study. Am Heart J 1993;125:838-47.

49. Appelman YEA, Piek JJ, de Feyter PJ, et al. Excimer laser coronary angioplasty versus balloon angioplasty used in long coronary lesions: the longterm results of the AMRO-trial [abstract]. J Am Coll Cardiol 1995;25: $329 \mathrm{~A}$. 